\title{
PATTERN DEVELOPMENT FOR MANUFACTURING APPLICATIONS WITH FUSED DEPOSITION MODELLING - A CASE STUDY
}

\author{
H. K. Garg ${ }^{1}$ and R. Singh ${ }^{2 *}$ \\ ${ }^{1}$ Faculty of Mechanical Engineering, GZS College of Engineering and Technology, \\ Bathinda, 151001, India, Phone: +919217689991, Fax: +911612502700 \\ ${ }^{2}$ Faculty of Production Engineering, Guru Nanak Dev Engineering College, \\ Ludhiana, 141006, India, Tel.: +919872257575, Fax: +911612502700 \\ *E-mail: rupindersingh78@yahoo.com
}

\begin{abstract}
The purpose of this paper is to examine the suitability of fused deposition modelling (FDM), for the production of a pattern that can be used in direct manufacturing applications. In this work, the benchmark was identified and its best part orientation in a FDM machine was located through experimentation. Control charts and process capability histogram were drawn to assess the process capability of the FDM process. The micro hardness of the prepared sample was measured to check the suitability of the process for investment casting applications. Further dimensional accuracy of patterns was established by IT grades as per the ISO standard UNI EN 20286-I (1995). It was observed that the performance indices for all the dimensions in the present study are greater than 1. The study of photo micrographs using SEM gave an insight into the properties of the component (produced by FDM). This study highlights that the tolerance grades for ABS plastics are consistent with the permissible range of tolerance grades as per the ISO standard UNI EN 20286-I (1995) and DIN16901 standard.
\end{abstract}

Keywords: Fused deposition modelling; photo micrographs; micro hardness; pattern; die; process capability.

\section{INTRODUCTION}

Rapid manufacturing (RM) is heralded as the next industrial revolution, as its impact is far reaching and the opportunities and advantages it offers are extensive (Singh and Garg, 2011; Kumar et al., 2012; Singh, 2013). RM parts are made using additive manufacturing technologies, and practically no waste material is generated (Kumar et al., 2013). Moreover RM can even be used in cases of complex geometries and has given freedom to new designs (Garg and Singh, 2012). For the production of moderate to high volumes of metal or plastic parts, moulding and casting are the prevalent processes (Garg and Singh, 2011). However, the tooling that is required demands a sizeable investment, and a significant amount of time is spent on the design of the product (Chabbra and Singh, 2011). RM is an enabling technology since it eliminates the upfront expense and expedites manufacturing (Jacobs and Hilton, 2000; Lee et al., 2004). A reduction in the product development cycle time is a major concern in industries who wish to remain competitive in the market place. Hence the focus has shifted from traditional product development methodology to rapid fabrication techniques like rapid prototyping (RP) (Tromans, 2003). With the concept of an improvement in accuracy and materials being considered, it can be envisioned to upgrade conventional techniques to the so-called RM techniques in which single parts 
are made which will be the end product rather than a prototype (Wohler, 2007). Product features, quality, cost and time to market are important factors for a manufacturer to remain competitive, and for this RP systems offer an opportunity to make products faster and usually at a lower price than convention methods (Agarwala et al., 1996).

$\mathrm{RM}$ is one of the many numbers of applications for component parts made using 'Additive Layer Manufacturing' (ALM) processes (Masood and Song, 2004). Other commercial applications for ALM within industry include the manufacture of prototypes, known as rapid prototyping, tool cores and cavities, known as rapid tooling (Gray et al., 1998), and in the manufacture of patterns for a range of casting processes, known as rapid casting (Kumar and Kruth, 2010). There has been an increase in the number of additive layer manufactured parts in recent years. RM is used for the manufacture of aerospace components, automotive applications, medical applications, motor sport parts (Pham and Gault, 1998) and consumer products, such as lightshades, furniture and football boots (Lam et al., 1998). RM has been identified as a possible catalyst for a 'new industrial revolution for the digital age'. The impact of RM on future engineering and manufacturing will undoubtedly be widespread. The various RP processes are fused deposition modelling (FDM), selective laser sintering (SLS), stereolithography (SL), laminated object manufacturing (LOM), etc. (Kumar et al., 2013). After 20 years of research, additive manufacturing (AM) continues to grow with the addition of new technologies, methods and applications (Lee et al., 2004). The FDM system has been commercially developed by Stratasys Inc. USA. In this process, FDM materials like ABS, elastomers, polycarbonates, polyphenol sulphones and investment casting wax feeds into the temperature-controlled FDM extrusion head, where it is heated to a semi-liquid state (Lee et al., 2007). The head extrudes and deposits the material in thin layers onto a fixtureless base. The head directs the material into place with precision, as each layer is extruded it bonds to the previous layer and solidifies. The designed object emerges as a solid three-dimensional part without the need for tooling. The FDM process is shown in Figure 1.

\section{EXPERIMENTATION}

In the present work, the benchmark was identified as a spanner which is representative of the hand tool industry and manufactured using FDM. The hand tool industry is a vibrant and developing industry, which can derive benefit from RP techniques. For conducting the experimentation, a CAD model of the benchmark (Figure 2) was made on UNIGRAPHICS software. The 3D CAD model was converted into the STL format, which was fed into the computer attached to the FDM machine for preparation of the component. The 3D model was converted into different $2 \mathrm{D}$ views, which are shown in Figure 3. The experimentation started with the identification of the best orientation. The machine was cleaned and the benchmark was set in default orientation as specified by the software. Thereafter the orientation was changed by varying the angles along the $X$, $\mathrm{Y}$ and $\mathrm{Z}$ axes of the FDM machine. The $\mathrm{X}$ and $\mathrm{Y}$ axes specify the movement of the ram, whereas the $\mathrm{Z}$ axis is the movement of the table in an up or down direction. After the setting of the orientations the component was sliced, layer by layer construction was carried out, and thereafter the components were cleaned. The best settings were identified based on the least consumption of support material, model material and the lowest production time. The consumption of the material and production time in different orientations is shown in Table 1. 


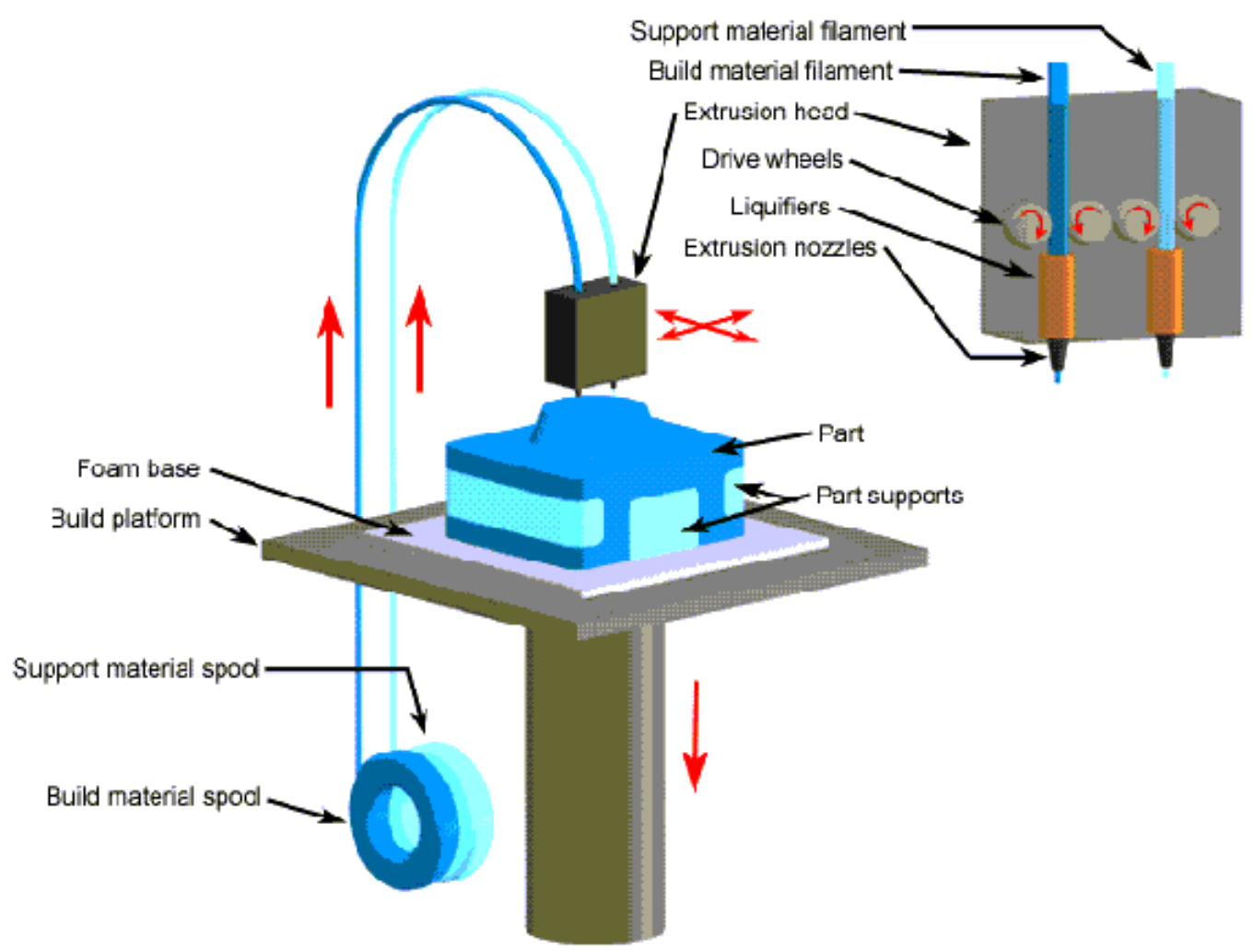

Figure 1. Schematic of FDM (Garg and Singh, 2011).

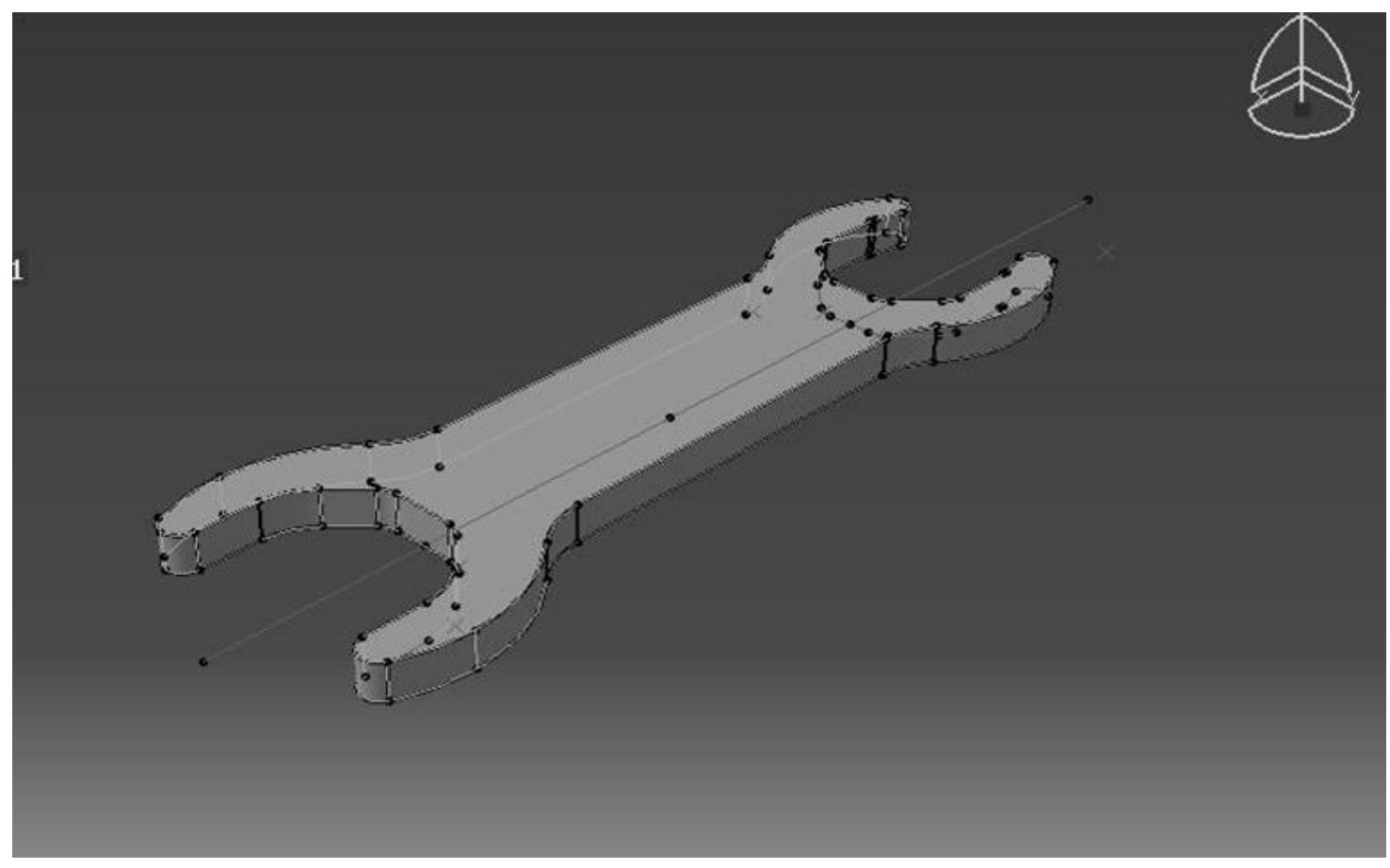

Figure 2. CAD model of benchmark. 


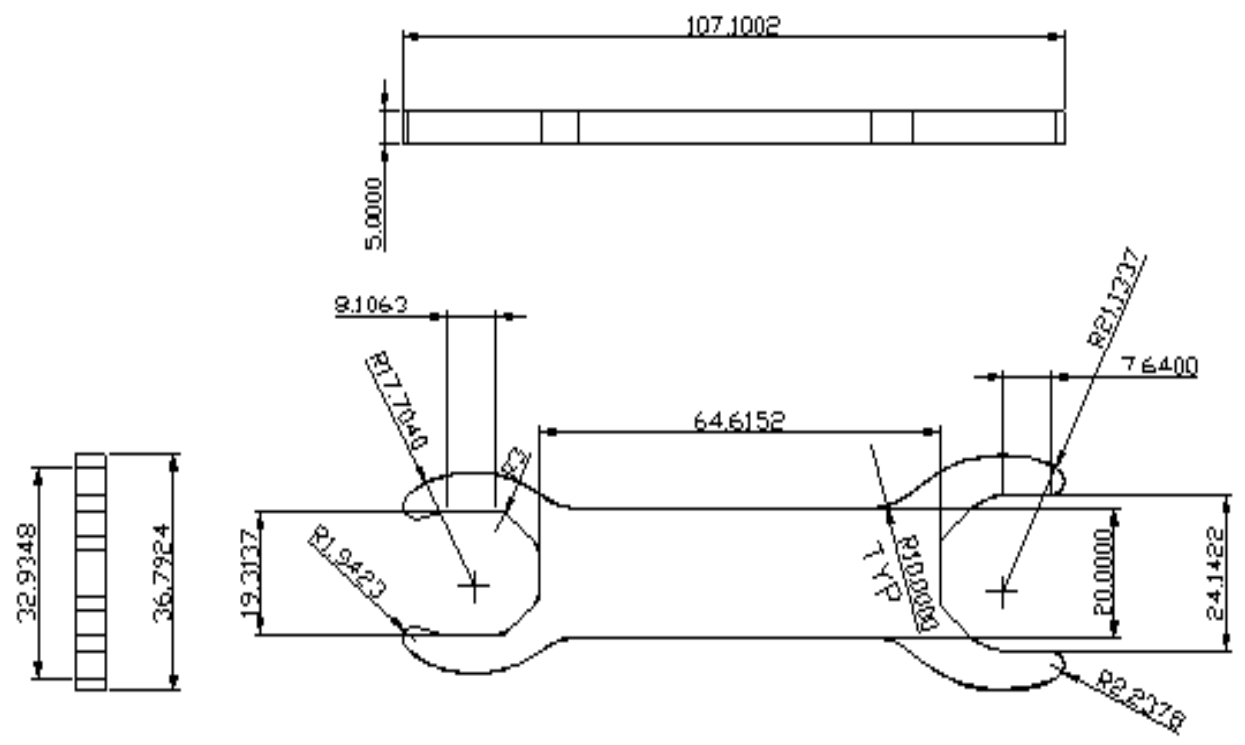

Figure 3. 2D views of benchmark.

Table 1. Different orientations of benchmark.

\begin{tabular}{|c|c|c|c|c|c|c|}
\hline Parameter & $\begin{array}{l}X=0^{0} \\
Y=0^{0} \\
Z=0^{0}\end{array}$ & $\begin{array}{l}X=30^{0} \\
Y=0^{\circ} \\
Z=0^{0}\end{array}$ & $\begin{array}{l}X=0^{0} \\
Y=30^{\circ} \\
Z=0^{0}\end{array}$ & $\begin{array}{l}X=0^{0} \\
Y=0^{0} \quad Z= \\
30^{0}\end{array}$ & $\begin{array}{l}X=60^{0} \\
Y=0^{\circ} \\
Z=0^{0}\end{array}$ & $\begin{array}{l}X=0^{0} \\
Y=60^{\circ} \\
Z=0^{0}\end{array}$ \\
\hline Model material $\left(\mathrm{mm}^{3}\right)$ & 8849 & 9012.9 & 9012.9 & 8849 & 8849.0 & 9012.9 \\
\hline Support material $\left(\mathrm{mm}^{3}\right)$ & 2294.2 & 8685.1 & 11634.8 & 6227.1 & 6227.1 & 5899.3 \\
\hline Time (hours) & 0.28 & 1.29 & 2.49 & 1.31 & 1.34 & 2.28 \\
\hline Parameter & $\begin{array}{l}X=0^{0} \\
Y=0^{0} \quad Z= \\
60^{0}\end{array}$ & $\begin{array}{l}X=0^{0} \\
Y=30^{\circ} \\
Z=30^{\circ}\end{array}$ & $\begin{array}{l}X=30^{\circ} \\
Y=0^{\circ} \\
Z=30^{\circ}\end{array}$ & $\begin{array}{l}X=30^{0} \\
Y=30^{\circ} \\
Z=0^{\circ}\end{array}$ & $\begin{array}{l}X=30^{\circ} \\
Y=30^{\circ} \\
Z=30^{\circ}\end{array}$ & $\begin{array}{l}X=60^{\circ} \\
Y=60^{\circ} \\
Z=60^{\circ}\end{array}$ \\
\hline Model material $\left(\mathrm{mm}^{3}\right)$ & 8849.0 & 8849 & 9012.9 & 8849 & 9012.9 & 9012.9 \\
\hline Support material $\left(\mathrm{mm}^{3}\right)$ & 6063.2 & 11470.9 & 9176.8 & 13601.3 & 13929 & 5571.6 \\
\hline Time (hours) & 2.71 & 2.21 & 1.26 & 2.38 & 2.39 & 2.29 \\
\hline
\end{tabular}

It was observed that the consumption of the model material in various orientations was more or less same, and is found to be $8849 \mathrm{~mm}^{3}$ or $9012.9 \mathrm{~mm}^{3}$. Consumption of the support material varied considerably between $2294.1 \mathrm{~mm}^{3}$ to $13601.3 \mathrm{~mm}^{3}$ for various orientations. A large variation in the production time was observed, ranging between 0.28 hours to 2.51 hours in various positions. The best orientation of the component leads to a reduced cost and reduced production time (Table 1). Photo micrographs of the manufactured component under different orientations were taken with a Scanning Electron Microscope (SEM) using gold plating. The photo micrographs was checked at the best settings (based on consumption of model material, support material and production time), at a rotation of $15^{\circ}$ to the best settings to the $\mathrm{X}$ axis and at a rotation of $30^{\circ}$ to the best settings to the $\mathrm{X}$ axis. The photo micrographs at the best settings, rotation at $15^{\circ}$ and $30^{\circ}$ degrees along the $\mathrm{X}$ axis, are shown in Figure 4 . The study of the photo micrographs revealed that the at the best settings of orientation, uniformly distributed grains are observed, which were closely packed compared to the 
position of $X=15^{\circ}$ and $X=30^{\circ}$, and on this basis it was concluded that the components produced in the horizontal position would be the best for the present case study.

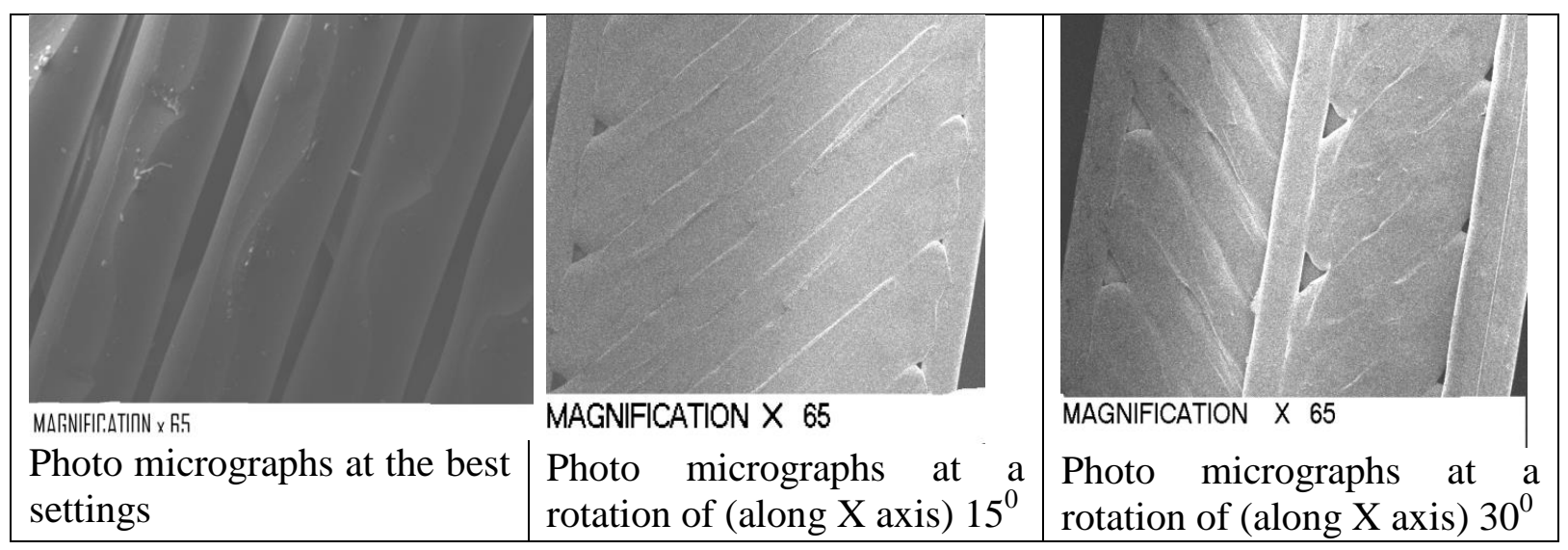

Figure 4. Photo micrographs at different orientations.

Table 2. Measured dimensions on coordinate measuring machine (Figure 3).

\begin{tabular}{lllllllll}
\hline Sample & \multicolumn{8}{c}{ Measured Dimension } \\
& \multicolumn{2}{c}{$\mathrm{D} 1$} & \multicolumn{2}{c}{$\mathrm{D} 2$} & \multicolumn{2}{c}{$\mathrm{D} 3$} & \multicolumn{2}{c}{$\mathrm{D} 4$} \\
& $(\mathrm{R} 17.7040 \mathrm{MM})$ & \multicolumn{2}{c}{$(36.7924 \mathrm{MM})$} & $(19.3137 \mathrm{MM})$ & \multicolumn{2}{c}{$(5.00 \mathrm{MM})$} \\
\hline & $1^{\text {st }}$ & $2^{\text {nd }}$ & $1^{\text {st }}$ & $2^{\text {nd }}$ & $1^{\text {st }}$ & $2^{\text {nd }}$ & $1^{\text {st }}$ & $2^{\text {nd }}$ \\
& piece & piece & piece & piece & piece & piece & piece & piece \\
\hline 1 & 17.6452 & 17.6643 & 36.7571 & 36.7211 & 19.2898 & 19.2641 & 5.1235 & 5.1111 \\
2 & 17.6693 & 17.6426 & 36.7508 & 36.7032 & 19.2814 & 19.2955 & 5.1147 & 5.1237 \\
3 & 17.6462 & 17.6567 & 36.7539 & 36.7163 & 19.3345 & 19.3273 & 5.1227 & 5.1097 \\
4 & 17.6547 & 17.669 & 36.7449 & 36.7641 & 19.3382 & 19.2843 & 5.0993 & 5.1101 \\
5 & 17.6558 & 17.6349 & 36.7245 & 36.7463 & 19.2873 & 19.3224 & 5.1079 & 5.1217 \\
6 & 17.6618 & 17.6299 & 36.7497 & 36.768 & 19.2739 & 19.2856 & 5.1178 & 5.1232 \\
7 & 17.6482 & 17.6353 & 36.7593 & 36.7239 & 19.3213 & 19.3336 & 5.1154 & 5.1044 \\
8 & 17.6571 & 17.6769 & 36.7475 & 36.7668 & 19.3253 & 19.2804 & 5.1073 & 5.1174 \\
9 & 17.6438 & 17.6633 & 36.7711 & 36.7148 & 19.3373 & 19.2931 & 5.1101 & 5.1198 \\
10 & 17.6768 & 17.6838 & 36.7514 & 36.7115 & 19.2805 & 19.3243 & 5.1127 & 5.0927 \\
11 & 17.6673 & 17.6866 & 36.7556 & 36.7224 & 19.3317 & 19.2847 & 5.0911 & 5.1125 \\
12 & 17.6419 & 17.6735 & 36.7117 & 36.7596 & 19.3345 & 19.2859 & 5.1018 & 5.1179 \\
13 & 17.6892 & 17.6559 & 36.7549 & 36.7331 & 19.3473 & 19.2843 & 5.1017 & 5.0987 \\
14 & 17.6794 & 17.6573 & 36.7624 & 36.7449 & 19.2843 & 19.3317 & 5.1049 & 5.1148 \\
15 & 17.6621 & 17.6726 & 36.7611 & 36.7278 & 19.3488 & 19.3243 & 5.1232 & 5.1118 \\
16 & 17.6598 & 17.6754 & 36.7742 & 36.7449 & 19.2843 & 19.3427 & 5.1082 & 5.1214 \\
\hline
\end{tabular}

Photo micrographs revealed the closeness and uniformity of bonding between adjacent beads under different orientations. At the best settings of orientation, uniformly distributed grains were obtained. It is observed that model material has not been deposited in certain places, and the number of places where material is left to be deposited is different under different orientations. This is because the deposition of material is dependent on the orientation of the benchmark. It is also observed that the size of the un-deposited model material also varies with the component orientations, as it is indicated that the space between 
beads is different in different orientations (Figure 4). It can be concluded that orientations of the benchmark are important to obtain the desired properties. Based on the best settings and photo micrographs, thirty-two pieces were manufactured on the FDM machine. Two pieces of the component were produced at a time, one after the other, and thereafter components were produced after 2 hours, resulting in a total of sixteen samples. The measurements of eight critical dimensions were made on the coordinate measuring machine and the results of the same are tabulated in Table 2 and 3.

Table 3. Measured dimensions on coordinate measuring machine (Figure 3).

\begin{tabular}{|c|c|c|c|c|c|c|c|c|}
\hline \multirow[t]{3}{*}{ Sample } & \multicolumn{8}{|c|}{ Measured dimension } \\
\hline & \multicolumn{2}{|c|}{$\begin{array}{c}\mathrm{D} 5 \\
(\mathrm{R} 1.9423 \mathrm{~mm})\end{array}$} & \multicolumn{2}{|c|}{$\begin{array}{c}\text { D6 } \\
(10.00 \mathrm{~mm})\end{array}$} & \multicolumn{2}{|c|}{$\begin{array}{c}\mathrm{D} 7 \\
(64.6152 \mathrm{~mm})\end{array}$} & \multicolumn{2}{|c|}{$\begin{array}{c}\text { D8 } \\
(20.00 \mathrm{~mm})\end{array}$} \\
\hline & $1^{\text {st }}$ piece & $\begin{array}{l}2^{\text {nd }} \\
\text { piece }\end{array}$ & $1^{\text {st }}$ piece & $\begin{array}{l}2^{\text {nd }} \\
\text { piece }\end{array}$ & $1^{\text {st }}$ piece & $\begin{array}{l}2^{\text {nd }} \\
\text { piece }\end{array}$ & $1^{\text {st }}$ piece & $2^{\text {nd }}$ piece \\
\hline 1 & 1.9201 & 1.9315 & 9.9416 & 9.9841 & 64.5644 & 64.6314 & 19.9532 & 19.9682 \\
\hline 2 & 1.9267 & 1.9206 & 9.9506 & 9.9887 & 64.5532 & 64.5251 & 19.9552 & 19.9774 \\
\hline 3 & 1.9322 & 1.9344 & 10.0391 & 10.0276 & 64.5651 & 64.5928 & 20.0482 & 20.0152 \\
\hline 4 & 1.9349 & 1.9383 & 10.0435 & 9.9898 & 64.5869 & 64.6466 & 20.0181 & 19.9856 \\
\hline 5 & 1.9307 & 1.9212 & 9.9603 & 10.0199 & 64.5756 & 64.5511 & 19.9506 & 20.0248 \\
\hline 6 & 1.9346 & 1.9209 & 9.9689 & 9.9884 & 64.5816 & 64.6375 & 19.9838 & 19.9668 \\
\hline 7 & 1.9384 & 1.9322 & 10.0276 & 10.0671 & 64.5808 & 64.5602 & 20.0222 & 20.0342 \\
\hline 8 & 1.9235 & 1.9334 & 10.0338 & 9.9878 & 64.5709 & 64.5537 & 20.0376 & 19.9836 \\
\hline 9 & 1.9368 & 1.9312 & 10.0224 & 10.0513 & 64.5572 & 64.5915 & 20.0248 & 20.03526 \\
\hline 10 & 1.9289 & 1.9205 & 9.9671 & 10.0105 & 64.6309 & 64.5803 & 19.9842 & 20.0214 \\
\hline 11 & 1.925 & 1.9326 & 10.0299 & 9.99 & 64.5757 & 64.5579 & 20.0398 & 19.9812 \\
\hline 12 & 1.9211 & 1.9288 & 10.0101 & 9.9699 & 64.5678 & 64.5818 & 20.0202 & 19.9798 \\
\hline 13 & 1.9249 & 1.9332 & 10.0328 & 9.9898 & 64.5844 & 64.6366 & 20.0416 & 19.9796 \\
\hline 14 & 1.9326 & 1.9249 & 9.9898 & 10.0299 & 64.5466 & 64.5857 & 19.9796 & 20.0318 \\
\hline 15 & 1.9289 & 1.9314 & 10.0232 & 10.0105 & 64.5624 & 64.5803 & 20.0364 & 20.021 \\
\hline 16 & 1.9327 & 1.9249 & 9.9898 & 10.0304 & 64.5866 & 64.5689 & 19.9796 & 20.0208 \\
\hline
\end{tabular}

\section{RESULTS AND DISCUSSION}

IT grades are an index to check the dimensional accuracy of components manufactured by any process. Tolerance factor ' $i$ ' is calculated for eight critical dimensions measured on CMM, and thereafter the tolerance unit ' $n$ ' is evaluated. This procedure is defined as per the ISO standard UNI EN 20286-I (1995).

$i=0.45 \times \mathrm{D} / 3 \pm 0.001 \times \mathrm{D}$

$\mathrm{D}$ is the geometric mean of range of the nominal size in $\mathrm{mm}$.

$n=1000\left(\mathrm{D}_{\mathrm{JN}}-\mathrm{D}_{\mathrm{JM}}\right) / i$,

$\mathrm{D}_{\mathrm{JM}}$ is the measured dimension and $\mathrm{D}_{\mathrm{JN}}$ is the nominal dimension. 
Table 4- IT grades for nominal dimension D1.

\begin{tabular}{llcllll}
\hline $\begin{array}{l}\text { Sample } \\
\text { No. }\end{array}$ & Dimension & $\mathrm{n}$ & $\begin{array}{l}\text { IT } \\
\text { Grade }\end{array}$ & $\begin{array}{l}\text { Dimension } \\
\text { Grade }\end{array}$ & $n$ & \\
\hline 1 & 17.6452 & 49.3895 & IT10 & 17.7040 & 33.3463 & IT9 \\
2 & 17.6693 & 29.1465 & IT9 & 17.6643 & 51.5733 & IT10 \\
3 & 17.6462 & 48.5495 & IT10 & 17.6426 & 39.7300 & IT9 \\
4 & 17.6547 & 41.4099 & IT10 & 17.6567 & 29.3985 & IT9 \\
5 & 17.6558 & 40.4859 & IT10 & 17.669 & 58.0410 & IT10 \\
6 & 17.6618 & 35.4462 & IT9 & 17.6349 & 62.2408 & IT10 \\
7 & 17.6482 & 46.8696 & IT10 & 17.6299 & 57.7050 & IT10 \\
8 & 17.6571 & 39.3940 & IT9 & 17.6353 & 22.7628 & IT8 \\
9 & 17.6438 & 50.5654 & IT10 & 17.6769 & 34.1862 & IT9 \\
10 & 17.6768 & 22.8468 & IT8 & 17.6633 & 16.9671 & IT8 \\
11 & 17.6673 & 30.8264 & IT9 & 17.6838 & 14.6152 & IT7 \\
12 & 17.6419 & 52.1613 & IT10 & 17.6866 & 25.6187 & IT9 \\
13 & 17.6892 & 12.4314 & IT7 & 17.6735 & 40.4019 & IT10 \\
14 & 17.6794 & 20.6629 & IT8 & 17.6559 & 39.2260 & IT9 \\
15 & 17.6621 & 35.1942 & IT9 & 17.6573 & 26.3746 & IT9 \\
16 & 17.6598 & 37.1261 & IT9 & 17.6726 & 24.0228 & IT8 \\
\hline
\end{tabular}

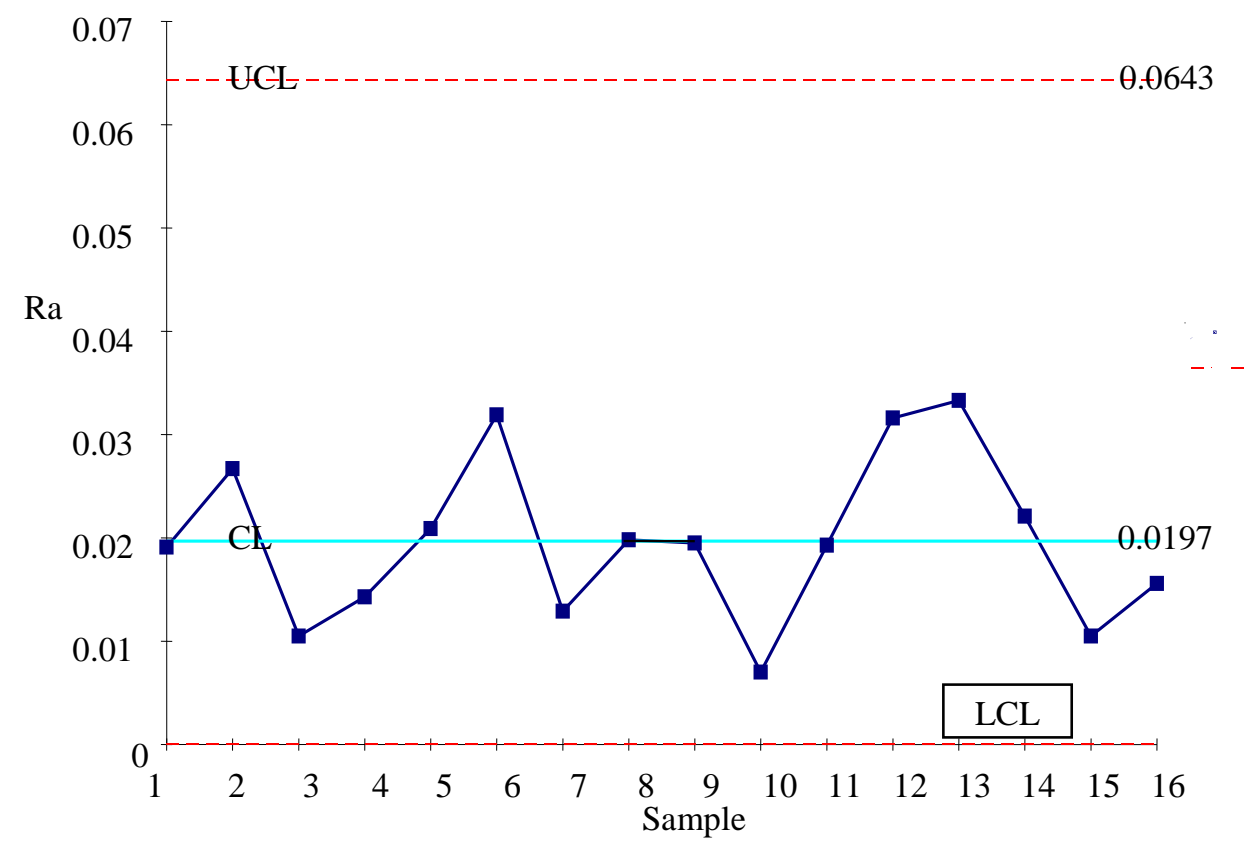

Figure 5. R chart for nominal dimension D1.

The results indicate that the majority of dimensions lay in the range of IT6 to IT10, which are consistent according to the ISO standard UNI EN 20286-I (1995) for a production process. Control charts are tools used to determine whether or not a manufacturing process is in a state of statistical controlprocess is said to be under statistical control if the measured values lie between +2 sigma and -2 sigma. Analysis of the control chart indicates that the process is currently under control, and that data from the process can be used to predict the future performance of the process. If the 
chart indicates that the process being monitored is not in control, analysis of the chart can help determine the sources of variation, which can then be eliminated to bring the process back into control. Figures 5 and 6 show the $\mathrm{X}$ bar and $\mathrm{R}$ chart for the nominal dimension D1.

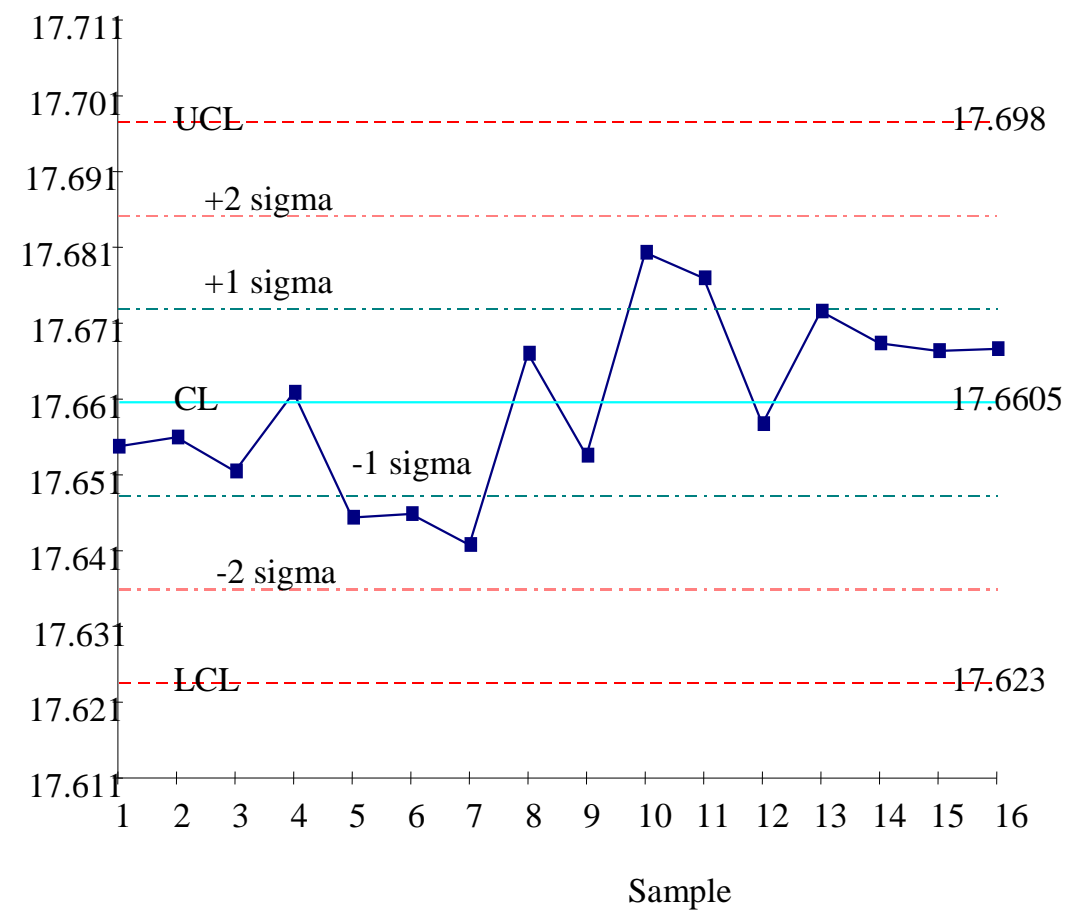

Figure 6. X chart for nominal dimension D1.

A study of the $\mathrm{X}$ bar and the $\mathrm{R}$ chart reveals that the measured dimensions in all cases were found to be within the 'Upper Control Limit (UCL) and Lower Control Limit (LCL)' from which it can be concluded that the process is in statistical control. The measured dimensions were found to lie between (+2sigma and -2sigma) in most of the cases. There was no chance variation, as not even a single observation went beyond the control limits. No unusual pattern, like too many points on one side of the mean or a gradual shift of the points towards LCL or UCL, was observed which indicated that there was no change in the production process as the measured values lay between the LCL and the UCL. It can be concluded that process is in a 'state of statistical control', with no special causes of variation. Capability analysis is a set of calculations used to assess whether a system is statistically able to meet a set of specifications or requirements. Process capability indices $(\mathrm{Cp}$ and $\mathrm{Cpk})$ are parameters that indicate the statistical capability of the process. Figure 7 shows the histogram for the process capability study for nominal dimension D1 with tolerances as per the DIN standards, while Figure 8 shows the histogram at reduced tolerances. The $\mathrm{X}$ axis of the histogram gives the classes and the $\mathrm{Y}$-axis the frequency... 


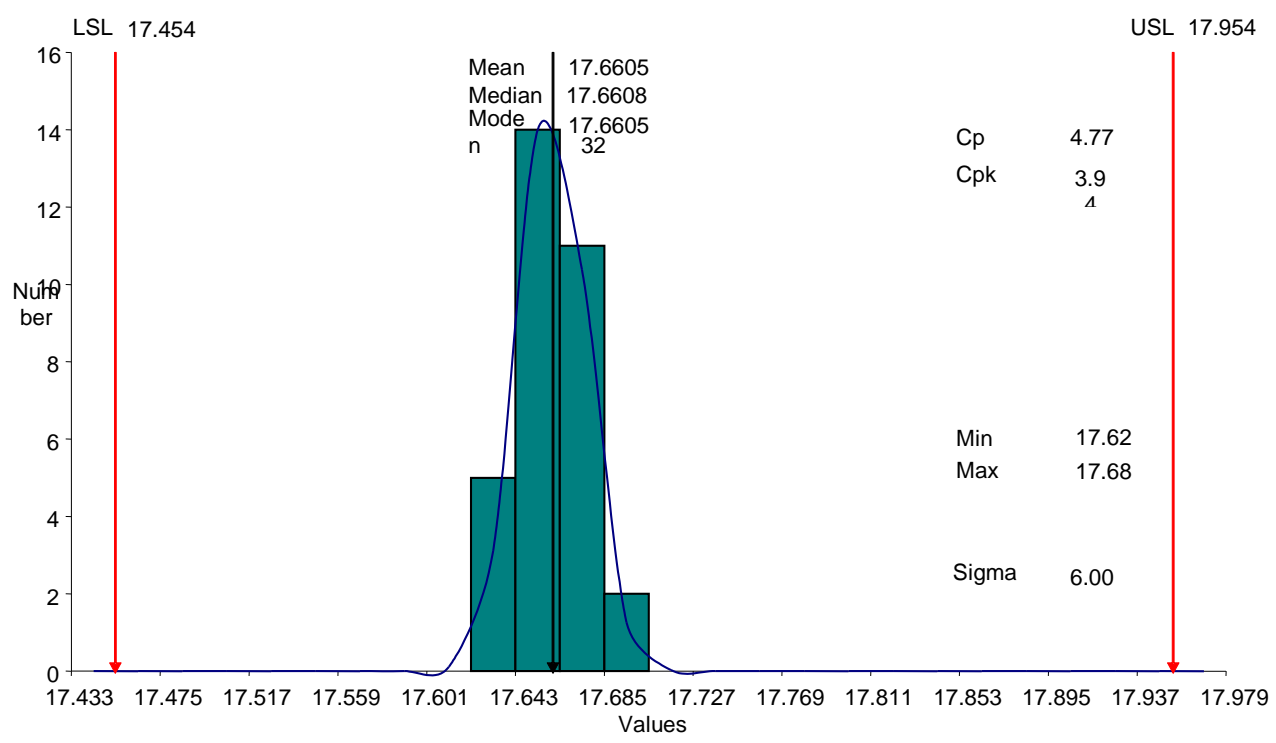

Figure 7. Histogram as per DIN standards.

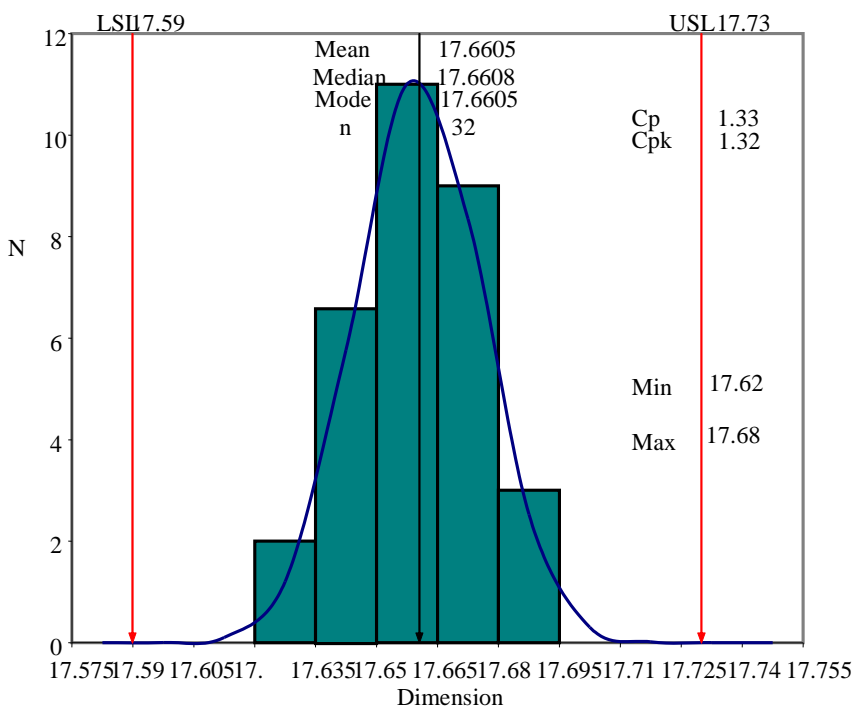

Figure 8. Histogram at reduced tolerances.

The value of the process capability indices ( $\mathrm{Cp}$ and $\mathrm{Cpk}$ ) has a value greater than 1 for all the dimensions, which is again an indication of good process capability. It can be established that the process distribution is centred within its limits. Furthermore, Table 5 shows the micro hardness of the benchmark. The uniform micro hardness of the manufactured part (pattern) is an indication of the process pattern and is helpful in producing sound castings. 
Table 5. Micro hardness of the benchmark.

\begin{tabular}{|c|c|c|c|c|c|c|c|}
\hline \multirow{2}{*}{$\begin{array}{r}\text { Sample } \\
\text { No. }\end{array}$} & \multicolumn{3}{|c|}{ Observations } & \multirow{2}{*}{$\begin{array}{r}\text { Sample } \\
\text { No. }\end{array}$} & \multicolumn{3}{|c|}{ Observations } \\
\hline & R1 & $\mathrm{R} 2$ & R3 & & $\mathrm{R} 1$ & R2 & R3 \\
\hline 1 & 325 & 335 & 332 & 17 & 348 & 355 & 342 \\
\hline 2 & 341 & 335 & 338 & 18 & 335 & 345 & 350 \\
\hline 3 & 352 & 348 & 346 & 19 & 348 & 347 & 336 \\
\hline 4 & 338 & 344 & 346 & 20 & 319 & 335 & 339 \\
\hline 5 & 341 & 343 & 340 & 21 & 337 & 353 & 342 \\
\hline 6 & 339 & 345 & 348 & 22 & 349 & 347 & 335 \\
\hline 7 & 344 & 347 & 350 & 23 & 328 & 348 & 337 \\
\hline 8 & 329 & 349 & 338 & 24 & 336 & 351 & 342 \\
\hline 9 & 345 & 351 & 342 & 25 & 351 & 346 & 345 \\
\hline 10 & 351 & 348 & 339 & 26 & 348 & 341 & 338 \\
\hline 11 & 331 & 338 & 348 & 27 & 327 & 342 & 348 \\
\hline 12 & 342 & 352 & 347 & 28 & 335 & 339 & 347 \\
\hline 13 & 334 & 344 & 349 & 29 & 344 & 340 & 348 \\
\hline 14 & 328 & 335 & 341 & 30 & 349 & 354 & 337 \\
\hline 15 & 342 & 328 & 335 & 31 & 345 & 340 & 334 \\
\hline 16 & 337 & 352 & 350 & 32 & 341 & 352 & 344 \\
\hline
\end{tabular}

The results obtained show that the micro hardness at different locations on the same sample was similar, which shows the uniformity with which the component is produced. It was also found to be uniform between the sample indicating there was no shift in the process and the process produced components of uniform properties. This was found in the range of 319 to 355 on the Vickers scale with an average value of 342 . This property of the process to produce parts of uniform hardness is helpful in producing sound castings. Table 6 shows the deviation of the measured maximum and minimum values from the actual dimensions of eight different dimensions. This deviation is an indication of how closely the FDM process is manufacturing the benchmark within the desired standards as prescribed by DIN 16901. This process produced a benchmark within close tolerances, as specified by the DIN 16901 standards. The average variation in dimensions is as low as 0.5 percent.

Table 6. Measured values vs. tolerance as per DIN standards.

\begin{tabular}{|c|c|c|c|c|c|c|}
\hline \multirow{2}{*}{$\begin{array}{c}\text { S. } \\
\text { No. }\end{array}$} & \multirow{2}{*}{$\begin{array}{c}\begin{array}{c}\text { Actual } \\
\text { dimension }\end{array} \\
\mathrm{mm}\end{array}$} & \multirow{2}{*}{$\begin{array}{c}\text { As per DIN } \\
\text { 16901Tolerance }\end{array}$} & \multicolumn{2}{|c|}{ Measured value $(\mathrm{mm})$} & \multicolumn{2}{|c|}{ Deviation from } \\
\hline & & & Maximum & Minimum & Maximum & Minimum \\
\hline 1 & 1.9423 & $+/-0.19$ & 1.9384 & 1.9201 & 0.004 & 0.022 \\
\hline 2 & 10.0000 & $+/-0.21$ & 10.0671 & 9.9416 & 0.067 & 0.058 \\
\hline 3 & 17.7040 & $+/-0.25$ & 17.6892 & 17.6299 & 0.015 & 0.074 \\
\hline 4 & 19.3137 & $+/-0.25$ & 19.3488 & 19.2641 & 0.035 & 0.050 \\
\hline 5 & 36.7924 & $+/-0.30$ & 36.7742 & 36.7032 & 0.018 & 0.089 \\
\hline 6 & 64.6152 & $+/-0.38$ & 64.6466 & 64.5251 & 0.031 & 0.090 \\
\hline 7 & 20.0000 & $+/-0.25$ & 20.0482 & 19.9506 & 0.048 & 0.049 \\
\hline 8 & 5.0000 & $+/-0.20$ & 5.1237 & 5.0801 & 0.124 & 0.080 \\
\hline
\end{tabular}




\section{CONCLUSIONS}

In this research work, the best orientation was chosen (that led to a considerable saving in support material and production time) for the development of a pattern for casting applications, and it was concluded from the study of photo micrographs at various orientations that the pattern of deposition of the model material depends on the orientation of the component. The tolerance grades for ABS plastics are consistent with the permissible range of tolerance grades (IT grades) as per the ISO standard UNI EN 20286-I (1995), and are also acceptable as per the DIN16901 standard. It is observed that the performance indices for all the dimensions in the present study are greater than 1. As the performance indices are greater than 1, which is considered the industry benchmark, so this process will produce conforming products as long as it remains in statistical control. The control charts reveal that the measured values lie between the limits, which shows that the process is in statistical control. The micro hardness showed that there is little variation in the hardness if taken at the same sample or on different samples, which indicated no shift in the process and that the process produces components of uniform strength. Finally, based upon better mechanical and metallurgical properties, it can be concluded that FDM can be suitably used for casting applications and can be gainfully used for job/batch production.

\section{REFERENCES}

Agarwala M.K., Van Weeren R., Bandyopadhyay A., Whalen P.J., Safari A. and Danforth S.C. 1996. Fused deposition of ceramics and metals; an overview. Proceedings of the Solid Freeform Fabrication Symposium, University of Texas, Austin, pp. 385-392.

Chabbra M. and Singh R. 2011. Rapid casting solution. Rapid Prototyping Journal, 17(5): 328-350.

Garg H.K. and Singh R. 2011. A framework for development of pattern for dies using FDM. International Journal of Advanced Mechatronics and Robotics, 3(2): 5360.

Garg H.K. and Singh R. 2012. Experimental investigations for development of pattern for dies using FDM. Material Science Forum, 701: 77-83.

Gray R.W., Baird D.G. and Bohn J.H. 1998. Effect of processing conditions on short TLCP fibre reinforced FDM parts. Rapid Prototyping Journal, 4(1): 14-25.

Jacobs P.F. and Hilton P.D. 2000. Rapid Tooling and Industrial Applications. Marcel Dekker, pp. 10-18. ISBN 9780824787882.

Kumar S. and Kruth J.P. 2010. Composites by rapid prototyping technology. Materials and Design, 31: 850-856.

Kumar P., Ahuja I.P.S., and Singh R. 2012. Application of FDM for rapid investment castings - a review. International Journal of Material Engineering and Innovation, 3(3-4): 204-227.

Kumar R., Singh R. and Ahuja I.P.S. 2013. Execution of RP technology - an Indian manufacturing industry perspective. International Journal of Indian Culture and Business Management, 6(2): 162-184.

Lam T.W., Yu K.M., Chueng K.M. and Li C.L. 1998. Reinforced thin shell objects rapid prototyping by fused deposition modeling. International Journal of Advanced Manufacturing Technology, 14: 631-638. 
Lee W., Chua C.K., Cheah C.M., Tan L.H. and Feng C. 2004. Rapid investment casting: direct and indirect approaches via fused deposition modeling. International Journal of Advanced Manufacturing Technology, 23: 93-101.

Lee C.S., Kim S.G., Kim H.J. and Ahn S.H. 2007. Measurement of anisotropic compressive strength of rapid prototyping parts. Journal of Materials Processing Technology, 207: 627-630.

Masood, S.H. and Song, W.Q. 2004. Development of new metal/polymer materials for rapid tooling using fused deposition modelling. Material and Design, 25(4): 587594.

Pham D.T. and Gault R.S. 1998. A comparison of rapid prototyping technologies. International Journal of Machine Tools \& Manufacture, 38: 1257-1287.

Singh R. and Garg H. K. 2011. Pattern Development for Hand Tool Die with Fused Ddeposition Modeling. Lambert Academic, Saarbrücken, Germany, ISBN: 9783-8433-8735-4

Singh R. 2013. Some investigations for small sized product fabrication with FDM for plastic components. Rapid Prototyping Journal, 19(1): 58-63

Tromans G. 2003. Developments in Rapid Casting. Professional Engineering, pp. 14-20. ISBN: 186058390392

Wohlers, T.T. 2007. Wohlers Report 2007: Exclusive Summery, Annual Worldwide Progress Report. Wohlers Associates, Fort Collins, CO. Available at: www.wohlersassociates.com/2001-exclusive-summary. 